\title{
ANALYSIS OF THE ASSURANCE OF WORK EXPERIENCE FOR UNIVERSITY GRADUATES IN THE CONTEXT OF INDUSTRY 4.0
}

\author{
VENDULA LACIOK ${ }^{1}$, ALES BERNATIK ${ }^{1}$, LENKA SVOBODOVA ${ }^{2}$, \\ IVETA MLEZIVOVA $^{2}$, VERONIKA HEJDOVA ${ }^{1} \&$ PAVEL SUSKA $^{1}$ \\ ${ }^{1}$ Faculty of Safety Engineering, VSB Technical University of Ostrava, Czech Republic \\ ${ }^{2}$ Occupational Safety Research Institute, Czech Republic
}

\begin{abstract}
Since the first industrial revolution, which brought us great inventions such as steam engines and the mechanical loom, society has entered new phases of revolution. Artificial intelligence (AI) and 3D printing are being introduced into the manufacturing business and the economy, while industry is facing new challenges in the fields of cyber-physical systems and information technology (IT). The overall concept of Industry 4.0 will impact not only industry, but also the areas of safety, the education system, the legal framework, science and research, and the social system. It is already necessary to start preparing the current generation for these new challenges and to develop the potential of mankind. This document is a result of the research project TL01000470 "Potential Impacts of Industry 4.0 on Operators in 3.0 Jobs and Tertiary Education in Accordance with Safety Engineering". This research can be considered the first step in an analysis to ensure that graduates gain significant practical experience in the context of Industry 4.0. This research project focuses on analysing the current situation on the labour market from the perspective of employers and their requirements of students and university graduates in the Czech Republic. The analysis focuses on knowledge of Industry 4.0 among students at the Faculty of Safety Engineering at VSB - Technical University of Ostrava. The state of preparedness for the world of work among graduates is inadequate from the practical viewpoint and it is essential to respond to the fourth industrial revolution by transforming the university syllabus.

Keywords: Industry 4.0, safety, student.
\end{abstract}

\section{INTRODUCTION}

The fourth industrial revolution (Industry 4.0) is being reflected progressively in every sector of national economies. Small, medium-sized and large concerns are beginning to apply the basic tools of Industry 4.0 and are digitalising process data, while other companies are introducing collaborative robots for work with man.

The approach to Industry 4.0 differs not merely in individual production sectors, but also beyond the borders of the Czech Republic. States take advantage of different means, finances and working groups, while there is also a functioning system of co-operation and projects serving as sources of inspiration and motivation for a further shift forwards in automation, digitalisation and the world of robots. Countries represent and define their progress and goals in Industry 4.0 with the help of initiatives and national programmes.

The World Economic Forum is devoting attention to Industry 4.0 on a broad scale. Since 1979 it has been issuing an annual report on the competitiveness of countries (the Global Competitiveness Report or GCR). This GCR considers and compares the performance economy in the areas of investments and information and communication technology on the basis of an index comprised of 12 predictors. It considers the following areas: institutions, infrastructure, the macroeconomic environment, education, the market in goods, the labour market, the financial market, technological readiness, the size of the market, business sophistication and innovation. The 2016 report is devoted to the preparedness of individual states for the challenge represented by Industry 4.0 [1]. Table 1 shows the ranking of 
Table 1: The ranking of states in the Global Competitiveness Report [2], [3].

\begin{tabular}{|l|c|c|}
\hline \multirow{2}{*}{ Name of country } & \multicolumn{2}{|c|}{ Placing in ranking (index value) } \\
\cline { 2 - 3 } & $2016-2017$ & $2017-2018$ \\
\hline Switzerland & $1(5.76)$ & $1(5.81)$ \\
\hline Singapore & $2(5.68)$ & $2(5.72)$ \\
\hline United States of America & $3(5.61)$ & $3(5.70)$ \\
\hline Netherlands & $5(5.50)$ & $4(5.57)$ \\
\hline Germany & $4(5.53)$ & $5(5.57)$ \\
\hline Sweden & $9(5.43)$ & $6(5.53)$ \\
\hline Great Britain & $10(5.43)$ & $7(5.49)$ \\
\hline Japan & $6(5.47)$ & $8(5.48)$ \\
\hline Finland & $8(5.45)$ & $10(5.44)$ \\
\hline Belgium & $19(5.20)$ & $17(5.25)$ \\
\hline Luxemburg & $20(5.20)$ & $20(5.20)$ \\
\hline France & $22(5.13)$ & $21(5.20)$ \\
\hline Australia & $21(5.15)$ & $22(5.19)$ \\
\hline Ireland & $24(5.11)$ & $23(5.18)$ \\
\hline Israel & $27(4.98)$ & $24(5.18)$ \\
\hline Republic of Korea & $26(4.99)$ & $26(5.03)$ \\
\hline China & $28(4.89)$ & $28(4.95)$ \\
\hline Czech Republic & $31(4.69)$ & $31(4.72)$ \\
\hline Russia & $45(4.44)$ & $43(4.51)$ \\
\hline Slovak Republic & $67(4.22)$ & $65(4.28)$ \\
\hline Ukraine & $79(4.04)$ & $85(4.00)$ \\
\hline
\end{tabular}

individual states in two time periods between 2016 and 2018. Switzerland, Singapore and the United States of America hold stable leading positions in the rankings. The Czech Republic in 31 st place, with an index value of 4.72 , is 1.09 index value points behind leading Switzerland.

If we compare the given states, Switzerland in first position and the Czech Republic, in the years 2017-2018 we can see in the following images the areas in which Switzerland is ahead (see Fig. 1). The Czech Republic can compete in the areas of health and education. Its weakest position, in contrast, is in the area of innovation. The dark highlighted area is the average of all states in the index.

The technological possibilities of Industry 4.0 are innumerable, with its limitations arising from human capital. Mařík [4] draws attention to the fact that the fourth industrial revolution is a more fundamental change in human thinking than in technology - we talk here of the term Thinking 4.0. Demands are placed on universities, which must change the content and style of tuition, and this itself imposes certain financial demands. Investment will move to education, where a change in the method of evaluation and management of universities will be required. 


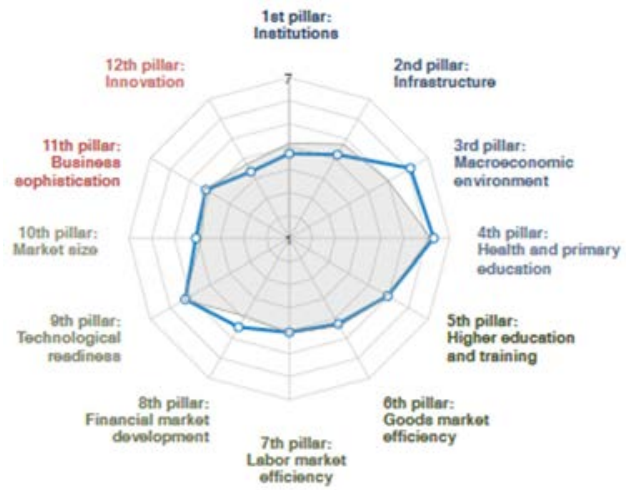

(a)

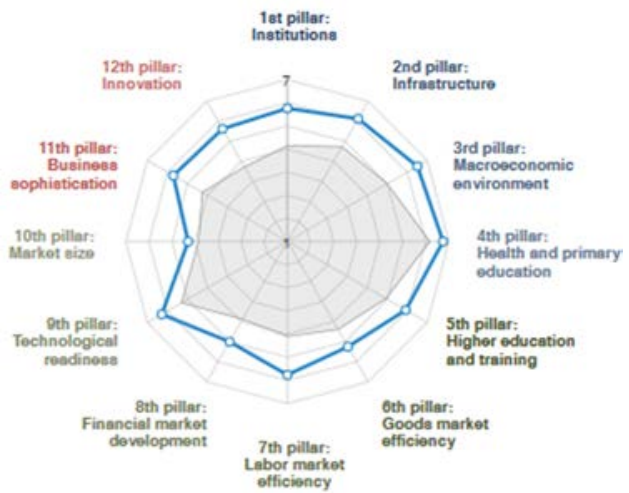

(b)

Figure 1: (a) Czech Republic 2017-2018; and (b) Switzerland 2017-2018 [3].

The main focus of this paper is analysis of the current situation on the labour market from the viewpoint of employers and their requirements of students and school leavers in the Czech Republic. This analysis focuses on students at the Faculty of Safety Engineering at VSB Technical University of Ostrava from the viewpoint of their knowledge of Industry 4.0.

\section{QUESTIONNAIRE SURVEY}

A quantitative method of public opinion research was used for pilot analysis, i.e. a questionnaire survey with the use of statistical techniques. The data obtained by the questionnaire survey was subjected to three hypotheses tested at the $5 \%$ level of significance $(\alpha=0.05)$. A test of goodness of fit (Pearson's qui-squared test), which is used on categorical data for comparing frequencies, was used to test the given hypotheses. The general formulation of the null and alternative hypothesis is as follows in this test:

- $\mathrm{H}_{0}$ : frequencies are equal;

- $\mathrm{H}_{\mathrm{A}}$ : frequencies differ significantly.

Equation for calculation of test statistics (1):

$$
\chi^{2}=\sum_{i=1}^{n} \frac{\left(O_{i}-E_{i}\right)^{2}}{E_{i}}
$$

where

$\mathrm{O}_{\mathrm{i}} \quad$ the observed frequency of the $i$ th group;

$\mathrm{E}_{\mathrm{i}} \quad$ the expected frequency of the $i$ th group;

$\mathrm{n}$ the number of groups;

$\chi^{2} \quad$ the qui-squared distribution value of the test statistics.

The value of the test statistics was transformed using the CHIDIST function to the attained value of significance ( $p$-value). This value was subsequently compared with the chosen level of significance $(\alpha)$. The null hypothesis was rejected in favour of the alternative hypothesis if the attained level of significance was lower than the chosen level of significance. The required calculations were performed in the software Microsoft Excel 2007. 


\subsection{The questionnaire survey of companies in the Czech Republic}

The first questionnaire comprised of 11 questions was concerned with research into enterprise entities in the context of Industry 4.0 in the Czech Republic. The aim of the questionnaire was to analyse the current situation at companies, particularly their position in relation to schools and their requirements of graduates. The target group were companies that have already introduced Industry 4.0 technology in order for their feedback to contribute to the future transformation of study fields responding to the fourth industrial revolution. The total number of questionnaires evaluated was 87 , of which 56 were from companies that have already introduced the given technology.

\subsubsection{Evaluation of the questionnaire}

The representation of respondents by size of company was relatively even. The greatest proportion of respondents represented enterprise entities in industry, i.e. the secondary sector, and amounted to 52 respondents. This was followed by the tertiary sector with 33 respondents representing services - transport, the health service, trade, education, cultural and communal services, science and research, high-tech technologies, etc. There was only minimal representation of the primary sector, amounting to just 2 respondents.

More than a half of the 87 respondents completing the questionnaire have already introduced Industry 4.0 technology at their companies. Fig. 2 depicts the technologies most strongly represented.

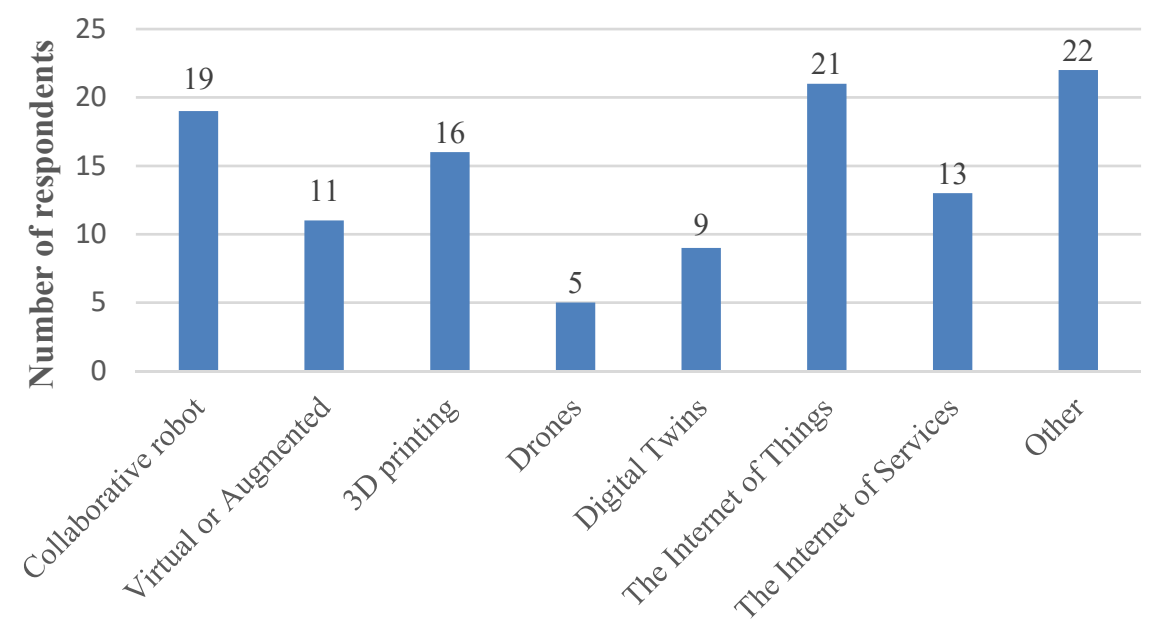

Technology 4.0

Figure 2: Industry 4.0 technologies represented among the questionnaire respondents.

Most of those questioned, i.e. $82 \%$, give preference to graduates of technical fields associated with work in industry. A total of $74 \%$ of respondents were/are in contact with a university within a framework of provision of work experience for students during the course of their studies. A number of companies offer paid work experience, though this is not a condition. The aim is to facilitate contact for students both with work experience and with potential future employment, giving companies the chance of gradually educating their own 
future employees. The research indicated that $26 \%$ of respondents have never engaged in cooperation with a university, i.e. 23 of the surveyed companies. 15 of these 23 surveyed companies would, however, welcome such co-operation in the future.

$74 \%$ of respondents gave preference to graduates with work experience. Conflict sometimes arises between study and work experience. There are groups of students that actively seek experience in the field during their bachelor studies, and these groups find it simpler to obtain valuable experience. There is then a group of students that devote themselves exclusively to their education during the course of their studies, and leave their initial contact with the world of work until after they have completed their education. In their job advertisements, companies often state the ambivalent words "suitable for graduates" and "we require at least 2 year's experience". One possible solution is greater emphasis on and motivation for the expansion of co-operation between companies and universities.

The respondents expressed rather similar views regarding the knowledge and skills that graduates should have after completing university. 53\% of those surveyed saw no lack of knowledge/skills in graduates. The remaining $47 \%$ saw a lack of experience in various areas. These areas were analysed and divided into groups. The first group contains knowledge that could be developed by students at university in the future within the scope of their study field: knowledge of the legislation (general safety, ATEX), mechanics, physics and materials, language skills, work experience, conscientiousness, a desire to learn new things, independence and analytical thinking. The second group contains knowledge relating to selected study fields. There is demand for students who have studied IT technologies, electrical engineering and engineering.

Responses to the final question indicate that companies want to invest means most often in 3D printing technology, expanded and virtual reality, and collaborative robotics.

\subsubsection{Hypothesis 1: The university at which an applicant has studied is not important to employers}

To test this hypothesis, we used the answers given to the question: "Do you give preference to particular universities at which applicants have studied?" The frequencies of the responses are summarised in Table 2.

Table 2: Observed and expected frequencies of responses for hypothesis 1.

\begin{tabular}{|l|c|c|}
\hline & Observed & Expected \\
\hline Yes & 19 & 43.5 \\
\hline No & 68 & 43.5 \\
\hline TOTAL & $\mathbf{8 7}$ & $\mathbf{8 7}$ \\
\hline
\end{tabular}

Hypotheses:

$$
\begin{aligned}
& \mathrm{H}_{0}: n_{N}=n_{Z}, \\
& \mathrm{H}_{\mathrm{A}}: n_{N} \neq n_{Z},
\end{aligned}
$$

where $n_{N}$ represents the frequency of respondents for whom the specific university attended is not important and $n_{Z}$ represents the frequency of respondents for whom the specific university attended is important.

Results:

$$
\chi^{2}=\frac{(19-43.5)^{2}}{43.5}+\frac{(68-43.5)^{2}}{43.5}=27.5977
$$




$$
p-\text { value }=1.49 * 10^{-7}
$$

\section{Conclusion:}

The attained level of significance $\left(1.49 * 10^{-7}\right)$ was smaller than the chosen level of significance (0.05). The test showed that the frequency differs significantly; essentially it was demonstrated that the frequency $n_{N}(68)$ is significantly different, i.e. higher, than frequency $n_{Z}$ (19), for which reason the examined hypothesis "The university attended is not important to employers" is confirmed at the $5 \%$ level of significance.

\subsubsection{Hypothesis 2: The knowledge of students is inadequate in relation to the} requirements of employers following completion of university

To test this hypothesis, we used the answers given to the question: "Have you ever felt a lack of specific knowledge or skills in employees in the context of your technology?" The frequencies of the responses are summarised in Table 3.

Table 3: Observed and expected frequencies of responses for hypothesis 2.

\begin{tabular}{|l|c|c|}
\hline & Observed & Expected \\
\hline Adequate & 54 & 43.5 \\
\hline Inadequate & 33 & 43.5 \\
\hline TOTAL & $\mathbf{8 7}$ & $\mathbf{8 7}$ \\
\hline
\end{tabular}

Hypotheses:

$$
\begin{aligned}
& \mathrm{H}_{0}: n_{N}=n_{D}, \\
& \mathrm{H}_{\mathrm{A}}: n_{N} \neq n_{D},
\end{aligned}
$$

where $n_{N}$ represents the frequency of respondents who felt a lack of specific knowledge or skills in graduates (they had inadequate knowledge) and $n_{D}$ represents the frequency of respondents who did not feel a lack of specific knowledge or skills in graduates (they had adequate knowledge).

Results:

$$
\begin{gathered}
\chi^{2}=\frac{(54-43.5)^{2}}{43.5}+\frac{(33-43.5)^{2}}{43.5}=5.069 \\
p-\text { value }=0.0243
\end{gathered}
$$

Conclusion:

The attained level of significance (0.0243) was smaller than the chosen level of significance (0.05). The test showed that the frequencies differ significantly; essentially it was demonstrated that the frequency $n_{N}(33)$ is significantly different, i.e. lower, than frequency $n_{D}$ (54). It is clear at first glance from the data that the hypothesis cannot be proven, for which reason our investigated hypothesis that "The knowledge of students following completion of university is inadequate in the context of the demands of employers" was rejected at the $5 \%$ level of significance.

2.1.4 Hypothesis 3: More than half of employers surveyed who are not engaged in co-operation with a university within the framework of work experience for students would welcome future co-operation

To test this hypothesis we used the responses to the questions "Have you ever engaged in cooperation with a university within the framework of work experience for students?" and "If not, would you welcome the introduction of co-operation on academic soil?" The frequencies 
of the responses of respondents who were not engaged in co-operation with a university are summarised in Table 4 along with the expected frequencies of the test of good fit.

Table 4: Observed and expected frequencies of responses for hypothesis 3.

\begin{tabular}{|l|c|c|}
\hline & Observed & Expected \\
\hline Would welcome & 15 & 11.5 \\
\hline Would not welcome & 8 & 11.5 \\
\hline TOTAL & $\mathbf{2 3}$ & $\mathbf{2 3}$ \\
\hline
\end{tabular}

Hypotheses:

$$
\begin{aligned}
& \mathrm{H}_{0}: n_{A N O}=n_{N E}, \\
& \mathrm{H}_{\mathrm{A}}: n_{A N O} \neq n_{N E},
\end{aligned}
$$

where $n_{A N O}$ represents the frequency of respondents who were not engaged in co-operation with a university, but would welcome future co-operation, and $n_{N E}$ represents the frequency of respondents who were also not engaged in co-operation with a university, but reject future co-operation with a university.

Results:

$$
\begin{gathered}
\chi^{2}=\frac{(15-11.5)^{2}}{11.5}+\frac{(8-11.5)^{2}}{11.5}=2.130 \\
p-\text { value }=0.144
\end{gathered}
$$

\section{Conclusion:}

The attained level of significance (0.144) was higher than the chosen level of significance (0.05), for which reason we do not reject the null hypothesis in favour of the alternative. The investigated hypothesis "More than half of surveyed employers who are not engaged in cooperation with a university within the framework of work experience for students would welcome future co-operation" could not be confirmed at the $5 \%$ level of significance.

\subsection{Questionnaire survey of students}

A second questionnaire investigated the awareness of students of Industry 4.0. The target group were students at the Faculty of Safety Engineering at VSB Technical University of Ostrava. A total of 70 students participated in the questionnaire survey, of which:

- 28 students in the first year of bachelor studies;

- 15 students in the second year of bachelor studies in the study field Safety of Work and Processes;

- 19 students in the third year of bachelor studies in the study field Safety of Work and Processes; and

- 8 students in the first year of master's studies in the study field Safety Engineering.

The questionnaire was comprised of five questions with a maximum score of six points. The boundary assessing success was set as a range of 4-6 points. Questionnaires with three points or less were assessed as unsuccessful. The aim was not the individual assessment of those completing the questionnaire, but merely a general overview of the basic knowledge the students have in the given area. 
2.2.1 Assessment of the first year of bachelor studies

Only 13 of the 28 students who completed the questionnaire achieved a successful score. The remaining 15 were counted as unsuccessful. The relative frequency of correct answers in the following graph indicated the lack of knowledge among the students answering the question "Which country is considered the cradle of Industry 4.0". Only three of the 28 students gave the correct answer-Germany. The remaining answers were assessed positively.

2.2.2 Assessment of the second year of bachelor studies

Only 7 of the 15 students who completed the questionnaire achieved a successful score of four points, i.e. less than half. This level of success is, therefore, comparable, with that of students in the first year of bachelor studies.

\subsubsection{Assessment of the third year of bachelor studies}

The least successful year from the viewpoint of our analysis is the third year of bachelor studies. Only three of the 19 students who completed the questionnaire achieved the successful score of four points. A total of 11 students attained a score of three points in the questions answered. Only $10 \%$ of these students completed the questionnaire successfully.

\subsubsection{Assessment of the first year of master's studies}

The smallest number of students in all the years analysed was seen in the first year of master's studies - eight respondents. Only two of these students attained the successful score of four points. In percentage terms, two successful questionnaires represents just $25 \%$, which is the second worst result of all years, regardless of the small group of those completing the questionnaire.

\subsubsection{Summary evaluation}

The most successful year in terms of the number of correct answers (a score of five points) is the second year of bachelor studies, followed by the third year. The difference between years two and three is $22 \%$. The first year of bachelor studies, with $46 \%$ success (success meaning at least four correct answers on the questionnaire) was ranked in third place. The first year of master's studies achieved the result of $25 \%$ with four correct answers, in spite of the low number of respondents. The average number of correct answers can be seen in Table 5.

Table 5: Average number of correct answers.

\begin{tabular}{|l|l|}
\hline 1st year of bachelor studies & 3.25 \\
\hline 2nd year of bachelor studies & 3.53 \\
\hline 3rd year of bachelor studies & 2.89 \\
\hline 1st year of master's studies & 2.75 \\
\hline
\end{tabular}

\section{DISCUSSION AND RECOMMENDATIONS}

Measures that could contribute towards assuring greater employability of graduates, particularly in Industry 4.0, are proposed in connection with the analyses performed. 
3.1 The amendment of curricula in the study programme Fire Protection and Industrial Safety, The Faculty of Safety Engineering at VSB - Technical University of Ostrava

Amendment to the subject Machinery, Equipment and Technology is recommended in the 1 st year of bachelor studies, which is the same for all first-year students.

Amendment to the subjects The Safety of Machinery and Equipment, Security Informatics, Technical Safety, The Psychology of Work Safety, and Risk Analysis and Danger is recommended in the 2nd, 3rd and 4th years of bachelor studies in the study field The Safety of Work and Processes.

Amendment to the subjects Diagnostics and Maintenance, and Developmental Trends in Safety Engineering is recommended in the 1st and 2nd years of master's studies in the study field Safety Engineering.

3.1.1 Specific exercises for students in the study field The Safety of Work and Processes Knowledge of the following legal standards is recommended for students within the framework of understanding the basic issues relating to collaborative robots (cobots):

- ISO 13482:2014 Robots and robotic devices - Safety requirements for personal care robots;

- ISO 15066:2016 Robots and robotic devices - Collaborative robots.

A cobot is more expensive and slower than a "normal" industrial robot, though more suitable for certain applications, even though it does not co-operate with man, because information on the pressure of its tensometers (sensors) can be used. A cobot can be viewed from two perspectives from the viewpoint of its use in practice:

1. The robot is in collaborative mode - in this case the ISO standard 15066:2016 applies, from the table of maximum forces (various forces for various parts of the body) that the robot can exert during contact with humans. Impact with any force to the head and neck is prohibited. If the robot fulfils these parameters, a person may approach to any distance. If the robot does not fulfil these parameters, it is necessary to calculate the safe distance for stoppage, this means

2. The robot in non-collaborative mode - the safe distance is calculated from CSN EN ISO 10218-1:2011 Robots and robotic equipment - Demands for the safety of industrial robots - Part 1: Robots. The minimum distance to the unsafe space must be calculated by the basic eqn (2):

$$
S=(K \times T)+C,
$$

where

$\mathrm{S} \quad$ is the minimum distance $(\mathrm{mm})$;

$\mathrm{K}$ the parameter of speed of approach $(\mathrm{mm} / \mathrm{s})$;

$\mathrm{T}$ the total period of system stoppage (s);

$\mathrm{C}$ the distance of penetration $(\mathrm{mm})$.

3.2 Increased awareness among students of Industry 4.0 in the form of lectures and seminars

This issue can also be incorporated into other subjects taught at faculties of VSB - Technical University of Ostrava to increase awareness of the fourth industrial revolution among students and draw attention to the importance of study of this issue. Lectures and seminars may be given by professors and engineers of other universities and by professionals owning 
and using 4.0 technology. In general terms, it is recommended that experts, company owners and company employees are engaged in education to a greater extent. The kind of lectures they give and their practical experience are extremely valuable and motivational for students, and this form of tuition operates in certain foreign countries.

3.3 Introduce intensive co-operation with the Czech Institute of Informatics, Robotics and Cybernetics (CIIRC), which is part of the Czech Technical University in Prague

CIIRC is a research centre and workplace in industry that is a highly regarded institute in the Czech Republic within and beyond the academic sphere. It also serves the students who visit it during their studies and who can try out practical procedures and technology here that will be, or already have been, introduced into industry. Part of CIIRC is a Testbed for Industry 4.0, which serves as a platform for contact between companies and the academic sphere. VSB - Technical University of Ostrava is also to have its own Testbed for Industry 4.0 in the near future, and the golden rule that the most effective way is to learn from the very best certainly continues to apply here.

3.4 Do more to address companies from all over the Czech Republic and introduce co-operation for the purpose of work experience for students during the course of their studies

Both the university and its individual faculties and students who can arrange co-operation near their homes can help expand this form of co-operation. Students can choose companies by either sector, size or principal area of business. A great way of repaying a company's loyalty is to invite it to the annual jobs fair Career PLUS where awareness of companies can be spread among the general public and where they can come into contact with students and the academic sphere.

\section{CONCLUSION}

This paper focuses on analysing the current situation on the labour market from the viewpoint of employers and their requirements of students and university graduates in the Czech Republic in connection with Industry 4.0. A questionnaire survey of companies, whose respondents were employers in various branches, was evaluated. The data obtained was subjected to three hypotheses tested at the 5\% level of significance. A test of good fit (Pearson's qui-squared test) was used to test these hypotheses. The awareness of Industry 4.0 among students at the Faculty of Safety Engineering at VSB - Technical University of Ostrava was analysed, and recommendations that may contribute towards assuring greater employability of graduates, particularly in the area of Industry 4.0, were proposed on the basis of the results of the questionnaire survey.

The introduction of trends of Industry 4.0, competitiveness, innovation, digitalisation and the creation of new job opportunities is conditional, to an ever increasing extent, on the use of new information and communication technologies (ICT). It is important that the population has the necessary knowledge and skills associated with the use of ICT. Their broader and more intensive use leads to growing demand for professionals who are capable of performing the great quantity of tasks associated with the development and maintenance of corporate ICT systems. In the Czech Republic, as in other countries, we have seen a trend in recent years towards an increasing proportion of concerns preferring to purchase ICT services rather than establish their own ICT departments. According to Eurostat research [5], concerns most frequently purchase activities related to the maintenance of ICT infrastructure 
(58\%), followed by activities associated with data security and protection (53\%) and the development and maintenance of webpages (49\%).

There is growing demand on the labour market for experts in the compilation, programming and administration of new technologies, business and data analysts, ICT project managers, ICT product dealers, security specialists and IT risk analysts, developers of web and mobile applications, software and graphics for the purposes of entertainment, experts in the development and support of cloud computing services, and embedded systems programmers. In the development of IT interfaces for human-machine work, for example, it will be necessary to have not just IT and technical knowledge, but also knowledge of, for example, ergonomics and the prevention of health risks. It can be said, in general terms, that the demand from companies for ICT professions will also increasingly include the demand and need for soft skills, enthusiasm for the field, communication skills, independence, initiative, the ability and willingness for continual self-education, flexibility, and logical and analytical thought. Higher positions will demand, first and foremost, managerial skills and creativity. It can be said in summary that companies expect of universities graduates with a multidisciplinary education who are creative, innovative and independent and, most importantly, who will have greater practical experience of the real working world.

Companies approach the employment of university graduates in two ways. The first seek suitable candidates for required positions on the labour market. An active approach is chosen, first and foremost, by larger companies who seek out their potential future employees among students with a suitable professional orientation. They often have a sophisticated training programme for students, offer work experience and provide suggestions for diploma subjects and guidance for students in co-operation with selected universities, or offer the chance of education for university students in a special education centre. They test potential job applicants in this way. This work experience is applied, first and foremost, by companies with foreign owners who have a sophisticated system of work with interns that is generally an adaptation of the system used at the parent company. Companies with Czech owners often complain of the fact that, given the shortage of graduates of ICT fields and the great demand for these professions on the labour market, they can compete with companies with foreign owners only with considerable difficulty in the acquisition of young professionals. Smaller companies give precedence to people with work experience when it comes to IT professions.

\section{ACKNOWLEDGEMENT}

The authors gratefully acknowledge the financial support of the project "Potential Impacts of Industry 4.0 on Operators in 3.0 Jobs and Tertiary Education in Accordance with Safety Engineering", identification code TL01000470.

\section{REFERENCES}

[1] Sankot, O., Global Competitiveness Report 2016-2017: Management summary. Competitiveness CZE 2017 - Digital Society, 2017. https://fmv.vse.cz/wpcontent/uploads/2016/09/manazerske_shrnuti_GCR_201617.pdf. Accessed on: 25 Feb. 2019. (In Czech.)

[2] Schwab, K. \& Sala-i-Martin, X., The Global Competitiveness Report 2016-2017. World Economic Forum, 2017. www3.weforum.org/docs/GCR20162017/ 05FullReport/TheGlobalCompetitivenessReport2016-2017_FINAL.pdf. Accessed on: 25 Feb. 2019.

[3] Schwab, K. \& Sala-i-Martin, X., The Global Competitiveness Report 2017-2018. World Economic Forum, 2018. www.weforum.org/reports/the-global-competitivenessreport-2017-2018. Accessed on: 25 Feb. 2019. 
32 Safety and Security Engineering VIII

[4] Mařík, V., What is Meant by Industrie 4.0 and Industry 4.0? Czech Institute of Informatics, Robotics, and Cybernetics (CIIRC), Czech Technical University in Prague, 2016.

[5] Eurostat, http://ec.europa.eu/eurostat/statistics-explained/index.php/ICT_specialists__statistics_on_hard-tofill_vacancies_in_enterprises. Accessed on: 25 May 2019. 